\title{
Synthesis of 1D, 2D, and 3D ZnO Polycrystalline Nanostructures Using the Sol-Gel Method
}

\author{
Yung-Kuan Tseng, ${ }^{1,2}$ Ming-Hung Chuang, ${ }^{2}$ Yen-Cheng Chen, ${ }^{2}$ and Chao-Hsien Wu ${ }^{2}$ \\ ${ }^{1}$ Department of Cultural Heritage Conservation, National Yunlin University of Science and Technology, Douliou 64002, Taiwan \\ ${ }^{2}$ Graduate School of Materials Science, National Yunlin University of Science and Technology, Douliou 64002, Taiwan
}

Correspondence should be addressed to Yung-Kuan Tseng, kuan@yuntech.edu.tw

Received 4 December 2011; Accepted 25 February 2012

Academic Editor: Yahya A. Ismail

Copyright ( 2012 Yung-Kuan Tseng et al. This is an open access article distributed under the Creative Commons Attribution License, which permits unrestricted use, distribution, and reproduction in any medium, provided the original work is properly cited.

\begin{abstract}
This study employed various polyol solvents to synthesize zinc oxide polycrystalline nanostructures in the form of fibers (1D), rhombic flakes $(2 \mathrm{D})$, and spheres $(3 \mathrm{D})$. The synthetic process primarily involved the use of zinc acetate dihydrate in polyol solutions, which were used to derive precursors of zinc alkoxides. Following hydrolysis at $160^{\circ} \mathrm{C}$, the zinc alkoxide particles selfassembled into polycrystalline nanostructures with different morphologies. Following calcination at $500^{\circ} \mathrm{C}$ for $1 \mathrm{~h}$, polycrystalline $\mathrm{ZnO}$ with good crystallinity was obtained. FE-SEM explored variations in surface morphology; XRD was used to analyze the crystalline structures and crystallinity of the products, which were confirmed as $\mathrm{ZnO}$ wurtzite structures. FE-TEM verified that the $\mathrm{ZnO}$ nanostructures were polycrystalline. Furthermore, we employed TGA/DSC to observe the phase transition. According to the results of property analyses, we proposed models of the relevant formation mechanisms. Finally, various $\mathrm{ZnO}$ structures were applied in the degradation of methylene blue to compare their photocatalytic efficiency.
\end{abstract}

\section{Introduction}

In recent years, zinc oxide $(\mathrm{ZnO})$ has become the subject of much research due to its excellent attributes as an IIVI semiconductor $[1,2]$. At room temperature, it possesses a wide direct band gap $(3.37 \mathrm{eV})$ as well as a high exciton binding energy of approximately $60 \mathrm{meV}$ [3]. By contrast, the free exciton binding energy of $\mathrm{GaN}$ is only $26 \mathrm{meV}$. Greater exciton binding energy enhances the light emission efficiency of excitons at room temperature [4], the mechanism of which can be applied in photoelectric conversion components, solar cells, UV lasers, piezoelectric and thermoelectric materials, nanometer photocatalysts, and gas sensors. Furthermore, $\mathrm{ZnO}$ has high thermal stability and UV absorption but does not absorb visible light, enabling its use in transparent conductive components. As well as titanium dioxide, $\mathrm{ZnO}$ is also an effective photocatalyst.

The application of $\mathrm{ZnO}$ nanostructures in nanodevices has attracted considerable attention in the last few years, leading to studies on various forms of syntheses. For example, many studies have conducted cylindrical, linear, and tubular forms of one-dimensional syntheses [5-9]; research on two-dimensional nanostructures is relatively rare [10-13]; more complex three-dimensional nanostructures are composed of low-dimensional nanostructures $[14,15]$.

Currently, there are many methods to fabricate $\mathrm{ZnO}$ nanostructures or microstructures. Oxidation of zinc vapor [16] involves placing metal zinc powder into a crucible and heating it in a furnace; at $419.53^{\circ} \mathrm{C}$, the powder melts into liquid state before evaporating into zinc vapor. Oxygen is introduced to react with the zinc vapor and form needleshaped crystal whiskers of $\mathrm{ZnO}$. Chemical vapor deposition (CVD) [17] is another approach that utilizes energy sources such as heat, plasma discharge, or UV irradiation to enable chemical reactions of vapor substances on the heated surface of a solid, where the stable solid products of the reaction are deposited. The vapor-liquid-solid method (VLS) [18, $19]$ is the most common process for the fabrication of $\mathrm{ZnO}$ nanostructures. High temperatures are required to vaporize or decompose $\mathrm{ZnO}$ growth sources; a catalyst and the resulting zinc vapor then produce an alloy with a low melting point. Zinc precipitates from the supersaturated 


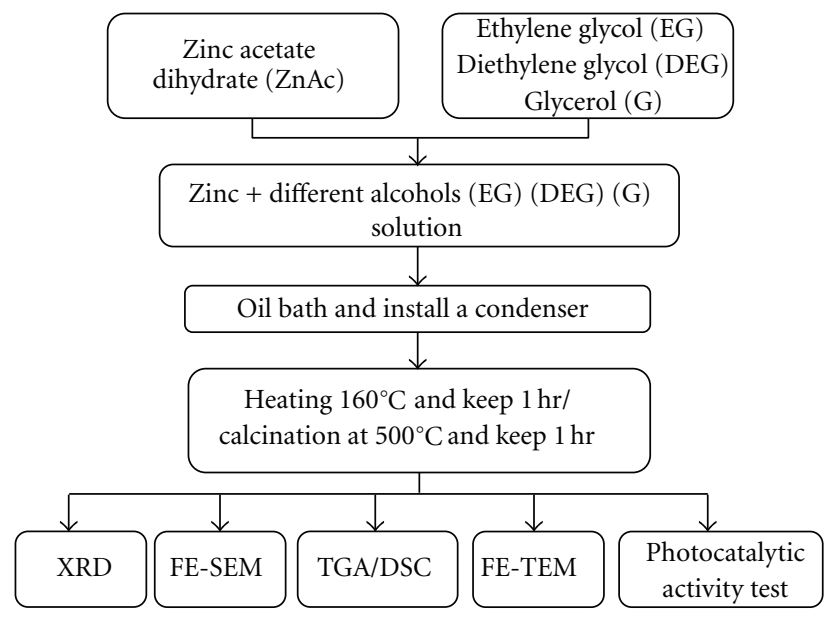

FIgURE 1: Procedure of the experiment.

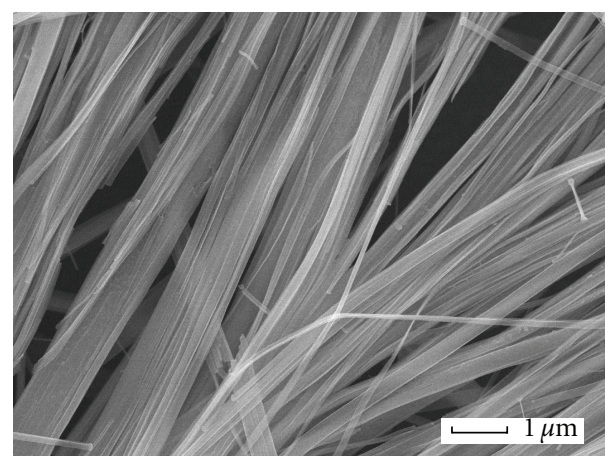

(a1)

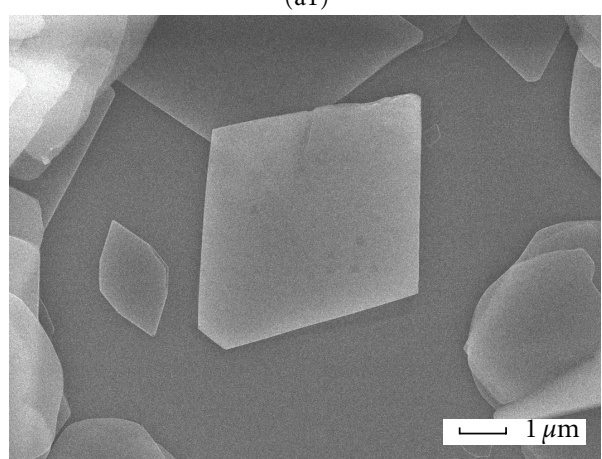

(b1)

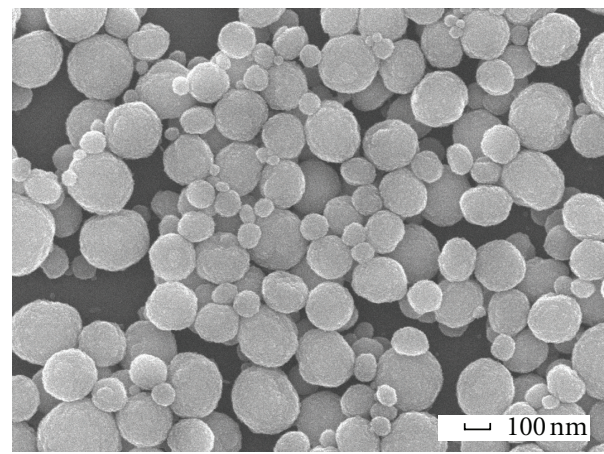

(c1)

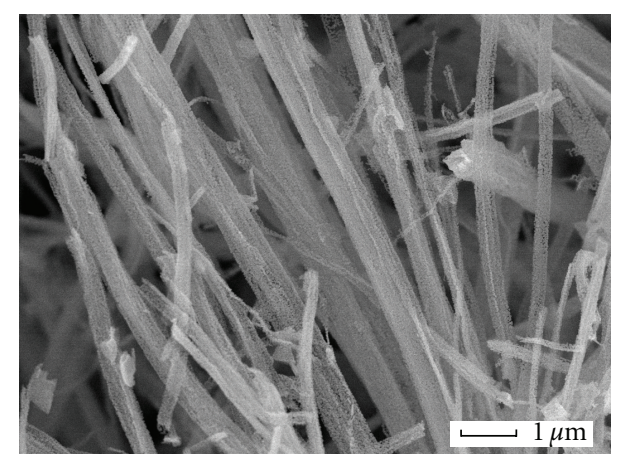

(a2)

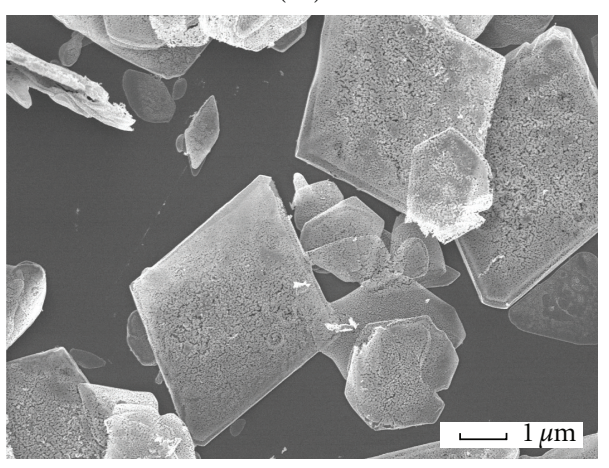

(b2)

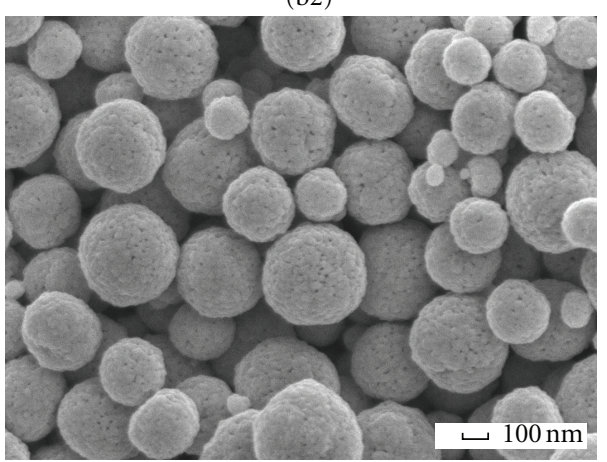

(c2)

Figure 2: Various surface morphologies of synthesized $\mathrm{ZnO}$ : (a1), (b1), and (c1) ZnO gel solutions dried at 160 ${ }^{\circ} \mathrm{C}$; (a2), (b2), and (c2) samples calcinated at $500^{\circ} \mathrm{C}$. 


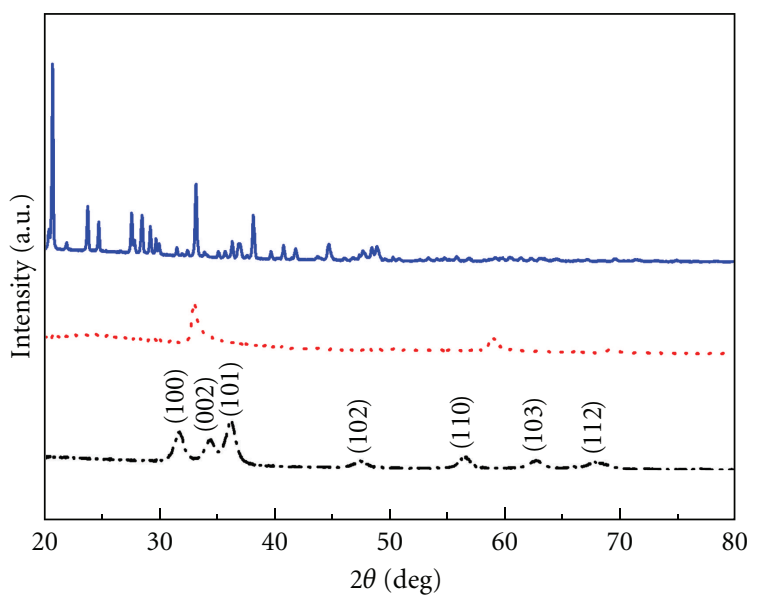

— ZnO sheets drying $\mathrm{ZnO}$ fibers drying ... $\mathrm{ZnO}$ spheres drying

(a)

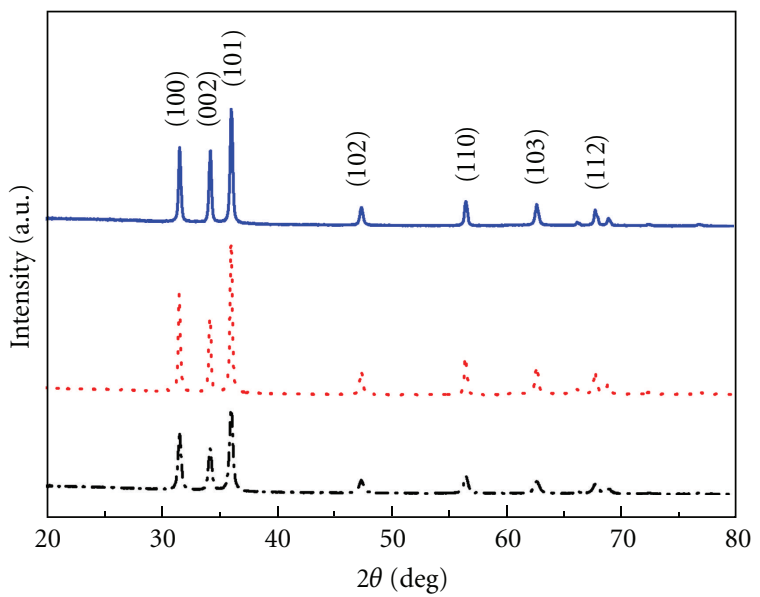

- $\mathrm{ZnO}$ sheets calcination $\mathrm{ZnO}$ fibers calcination -. - ZnO spheres calcination

(b)

Figure 3: $\mathrm{XRD}$ graphs of $\mathrm{ZnO}$ fibers, $\mathrm{ZnO}$ spheres, and $\mathrm{ZnO}$ flakes following (a) drying at $160^{\circ} \mathrm{C}$ and (b) calcination at $500^{\circ} \mathrm{C}$.

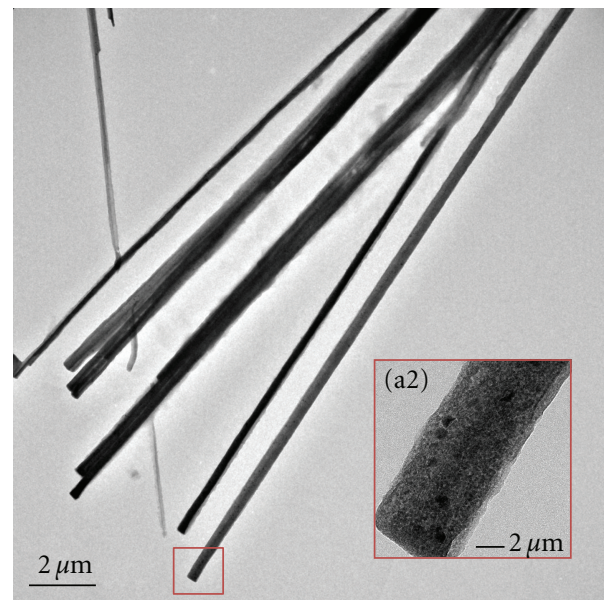

(a1)

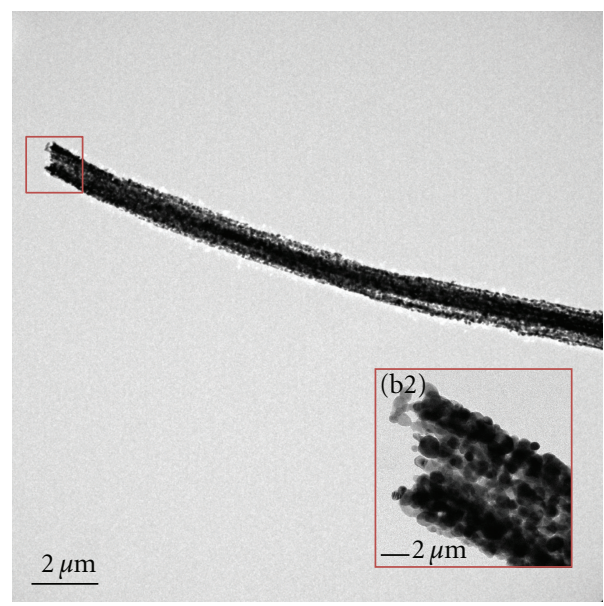

(b1)

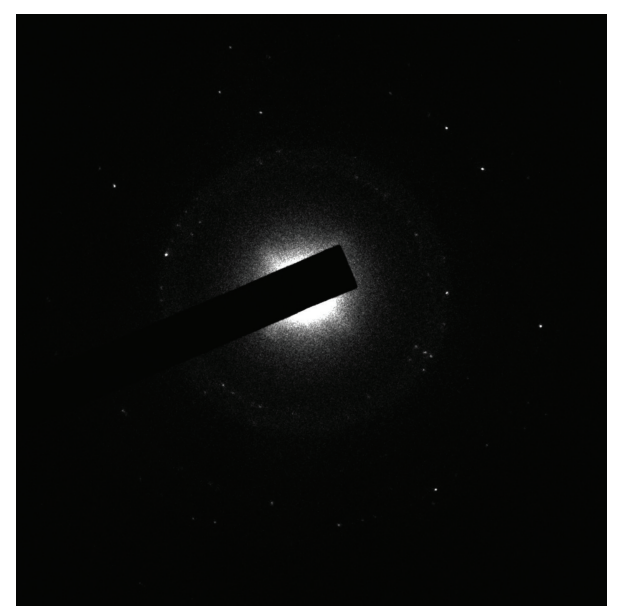

(a3)

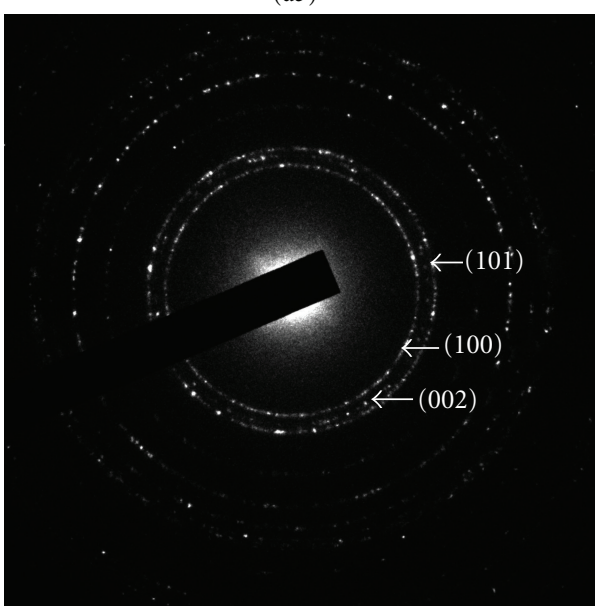

(b3)

Figure 4: SAED graphs and FE-TEM images of ZnO fibers: (a1), (a2), and (a3) samples dried at $160^{\circ} \mathrm{C}$; (b1), (b2), and (b3) samples calcinated at $500^{\circ} \mathrm{C}$. 


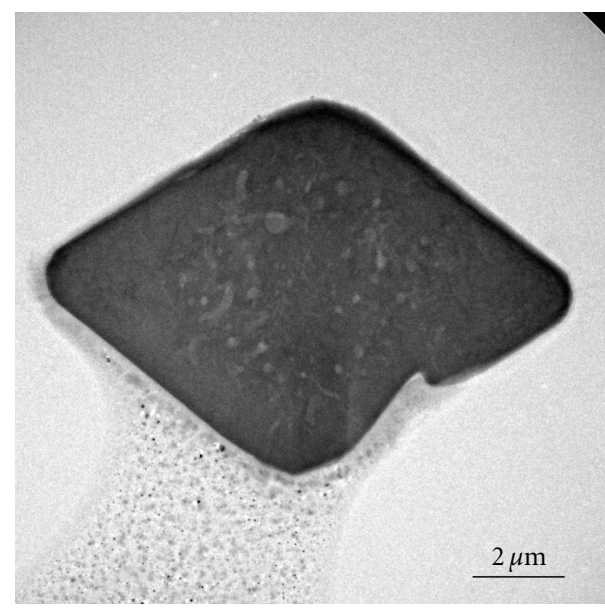

(a1)

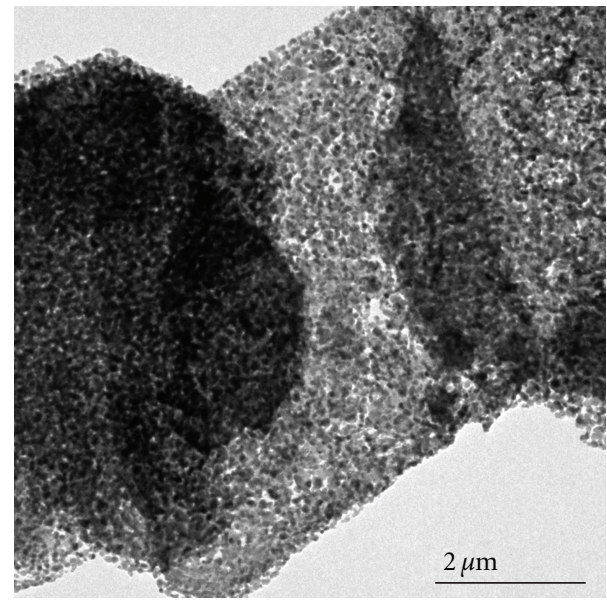

(b1)

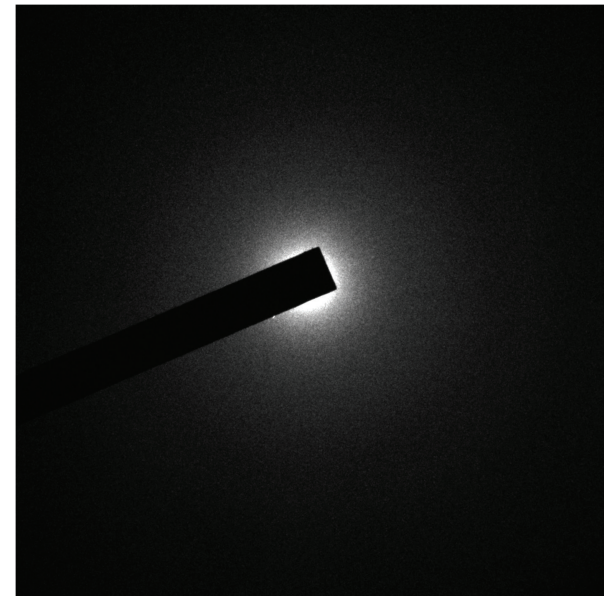

(a2)

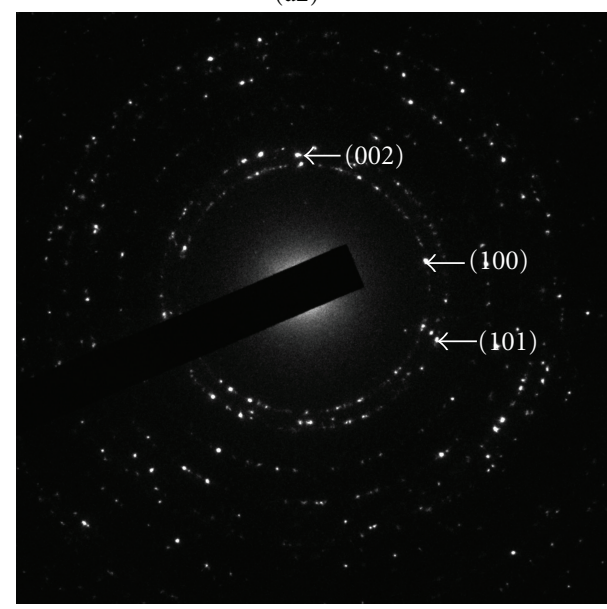

(b2)

FIGURE 5: SAED graphs and FE-TEM images of ZnO flakes: (a1) and (a2) samples dried at $160^{\circ} \mathrm{C}$; (b1) and (b2) samples calcinated at 500 ${ }^{\circ} \mathrm{C}$.

alloy before merging with atmospheric oxygen to form $\mathrm{ZnO}$ nanowires. The $\mathrm{ZnO}$ nanowires synthesized via the VLS method are generally monocrystalline, the diameter of which is determined by the particle size of the catalyst. Finally, the template-based method [20] employs methods such as electroplating, CVD, and the sol-gel method to grow the desired substance in the holes of a porous alumina substrate, the growth template. The $\mathrm{ZnO}$ nanostructures obtained from this method are polycrystalline.

Regardless of monocrystalline or polycrystalline results, most methods for producing $\mathrm{ZnO}$ structures require high temperatures or high costs. This study proposes a low-cost sol-gel method to fabricate various forms of $\mathrm{ZnO}$ structures. This novel process is fast and can be completed at lower temperatures. Moreover, the photocatalytic effect of the fiber $\mathrm{ZnO}$ structures produced with ethylene glycol as the solvent is superior to that of commercial $\mathrm{ZnO}$.

\section{Experiment Methods}

2.1. Synthesis. All of the chemicals employed in this study were of analytical grade and required no further purification.
This study employed three alcohols as solvents in the sol-gel method to fabricate various $\mathrm{ZnO}$ nanostructures: ethylene glycol (EG), glycerol (G), and diethylene glycol (DEG). The structural, physical, and optical properties of the $\mathrm{ZnO}$ products generated from the three solvents were compared.

The synthesis was divided into three processes: solution preparation, heating to promote hydrolysis, and heat treatment of the products.

The steps involved in the synthesis are as follows.

(1) $0.1 \mathrm{M}$ of zinc acetate dihydrate $\left(\mathrm{Zn}\left(\mathrm{CH}_{3} \mathrm{COO}\right)_{2}\right.$. $2 \mathrm{H}_{2} \mathrm{O}$ ) is placed in a $250 \mathrm{~mL}$ round-bottom flask.

(2) $100 \mathrm{~mL}$ of the solvent (EG, G, or DEG) is added to the flask.

(3) The round-bottom flask is equipped with a reflux apparatus and placed in an oil bath, where the solution is heated and stirred.

(4) The solution is heated at a rate of $1^{\circ} \mathrm{C} / \mathrm{min}$. When the temperature approaches $160^{\circ} \mathrm{C}$, the clear solution becomes milky white. The temperature of the solution is maintained at $160^{\circ} \mathrm{C}$ for $1 \mathrm{~h}$. 


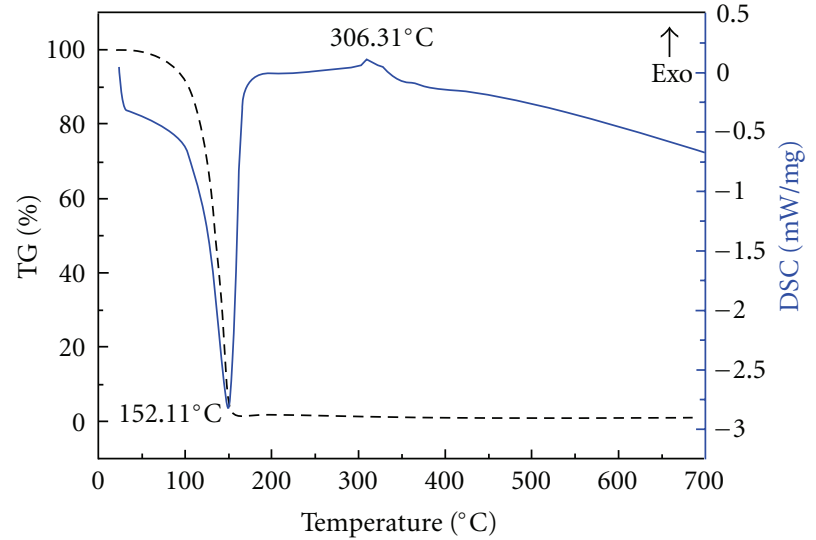

(a) Fibers

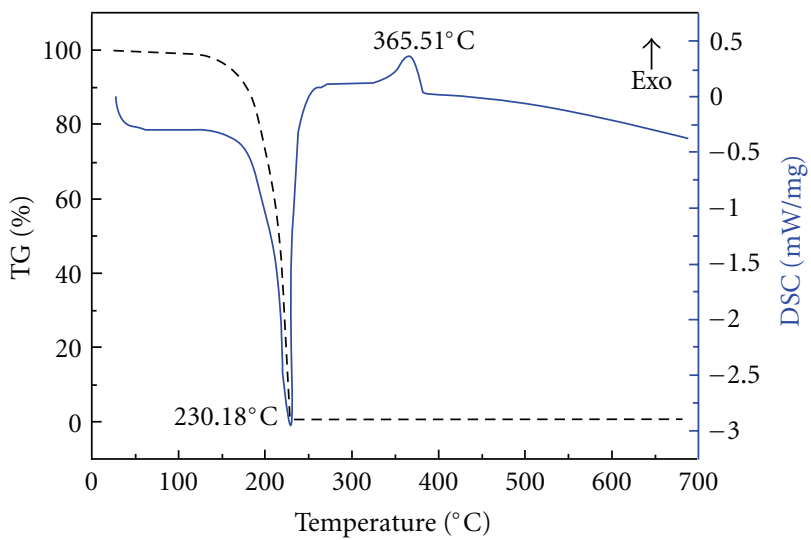

(b) Flakes

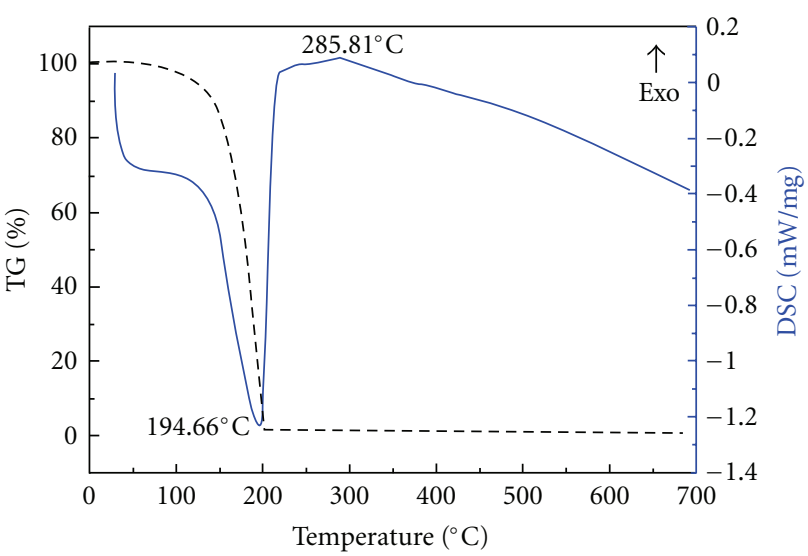

(c) Spheres

FIGURE 6: TGA/DSC graphs of the precursor of various $\mathrm{ZnO}$ structures: (a) fibers, (b) flakes, and (c) spheres.

(5) The milky white solution is dripped onto silicon substrates and dried on a hot plate at $160^{\circ} \mathrm{C}$, forming one sample type. For the other sample type, the solution is placed in a high-temperature furnace and heated to $500^{\circ} \mathrm{C}$ at a rate of $5^{\circ} \mathrm{C} / \mathrm{min}$ under atmospheric conditions. The temperature is maintained for $1 \mathrm{~h}$, and the sample is taken out once its temperature cools to room temperature.

The experimental procedure is illustrated in Figure 1.

2.2. Property Analysis. Field emission scanning electron microscopy (FE-SEM, JEOL JSM7500F) was performed on the sample dried at $160^{\circ} \mathrm{C}$ and the sample calcinated at $500^{\circ} \mathrm{C}$ to explore their surface morphology. High-resolution X-ray diffraction (HR-XRD, PHILIPS X'PERT Pro MPD) was employed to analyze the structural properties of the samples, and the phase transition during the synthetic process was observed using simultaneous thermogravimetric analyzer and differential scanning calorimeter (TGA/DSC, TA Instruments-SDT 2960). A field emission transmission electron microscope (FE-TEM JEOL JEM-2100F) was used to observe the appearance and crystalline structure.
2.3. Photocatalytic Activity Test. Three different morphologies of synthesized $\mathrm{ZnO}$ were compared with commercial $\mathrm{ZnO}$. Samples were placed in methylene blue solutions and exposed to UV-C light for an hour. The absorption values of the samples were measured every 20 min using UV-visible spectroscopy (JASCO V-630).

\section{Results and Discussion}

3.1. Surface Morphology. From FE-SEM observations, this study determined that the application of zinc acetate dihydrate as a solute in conjunction with EG, G, and DEG as solvents in sol-gel reactions enables the formation of $\mathrm{ZnO}$ with varying morphologies. Figure 2 presents the various types of $\mathrm{ZnO}$ that can be obtained from $\mathrm{ZnAc}$ with various polyols and heat treatments. Using EG, G, and DEG as the solvents resulted in fiber structures (Figures 2 (a1) and 2(a2)), flake structures (Figures 2(b1) and 2(b2)), and spherical structures (Figures 2(c1) and 2(c2)), respectively. All of the samples with gel solutions synthesized at $160^{\circ} \mathrm{C}$ and then dried on a hot plate at $160^{\circ} \mathrm{C}$ presented a smooth micromorphology (Figures 2(a1), 2(b1), and 2(c1)). The samples 


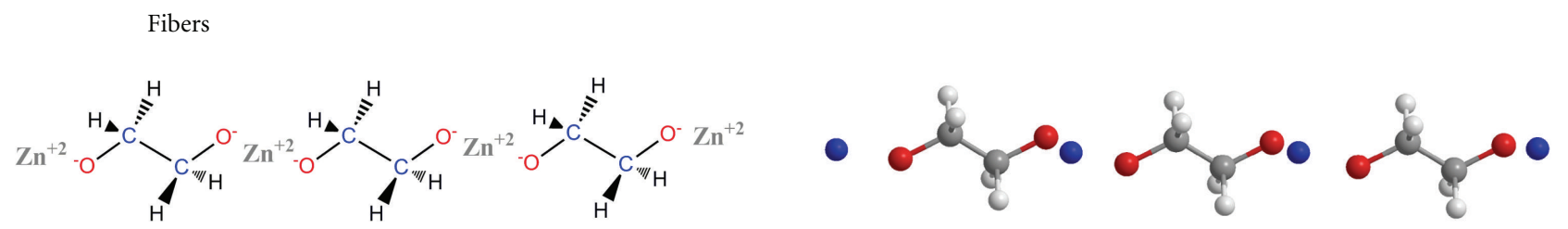

(a)

Flakes
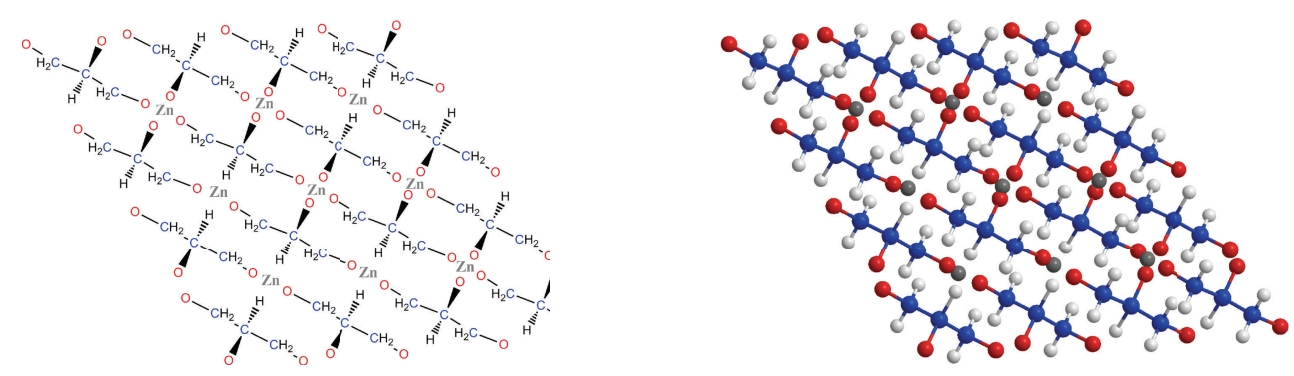

(b)

Spheres
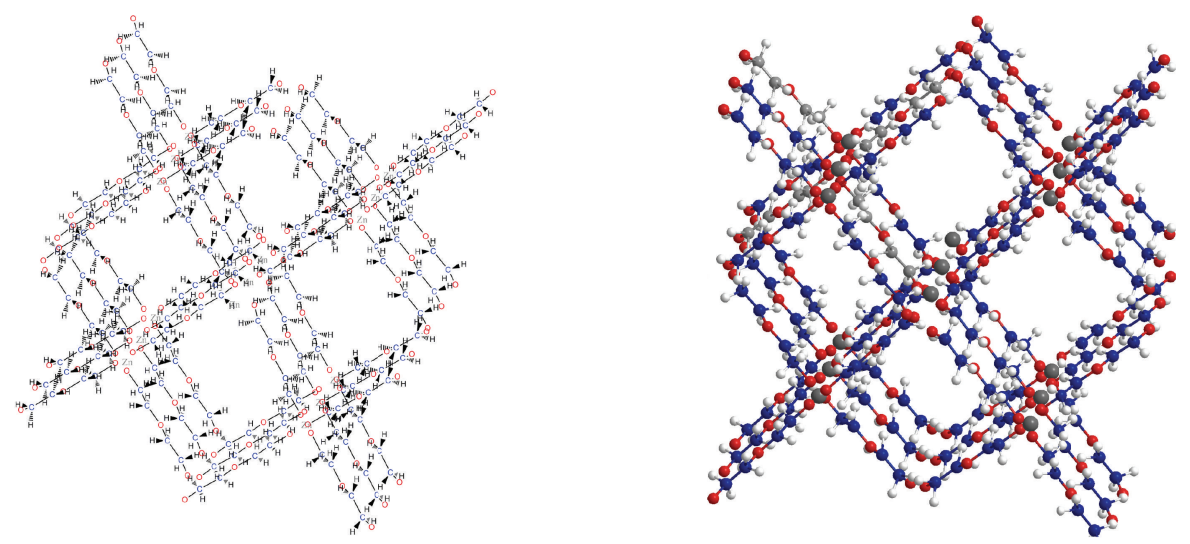

(c)

FIGURE 7: Formation mechanisms of $\mathrm{ZnO}$ fibers (1D), ZnO flakes (2D), and $\mathrm{ZnO}$ spheres (3D). Color code: blue: carbon, white: hydrogen, red: oxygen, and grey: zinc.

calcinated in air at $500^{\circ} \mathrm{C}$ remained unchanged in shape but exhibited rougher surfaces with additional holes and cracks (Figures 2(a2), 2(b2), and 2(c2)), which were due to the conversion of the larger zinc alkoxide particles into the smaller $\mathrm{ZnO}$ crystals.

3.2. Structural Properties. Figure 3 shows the XRD graphs of the three types of zinc compound dried at $160^{\circ} \mathrm{C}$ and calcinated at $500^{\circ} \mathrm{C}$. The graphs of the samples dried at $160^{\circ} \mathrm{C}$ were compared with JCPDS files, of which no files were found to be identical to the $\mathrm{ZnO}$ flakes and fibers. No similar graphs were found in the literature either. We speculate that the two XRD graphs are consistent with the crystal structure of zinc alkoxides. The spherical structures dried at $160^{\circ} \mathrm{C}$ are consistent with $\mathrm{ZnO}$ structures, as shown in Figure 3(a). This indicates that using DEG as the solvent can hydrolyze $\mathrm{ZnAc}$ into $\mathrm{ZnO}$ at lower temperatures. Regarding the three samples calcinated at $500^{\circ} \mathrm{C}$, the XRD graphs were recognized as identical to nos. $36-1451$ in the JCPDS files, namely, wurtzite structures (Figure 3(b)).

Figure 4 shows the appearance and crystalline structure of the zinc compounds observed by FE-TEM. Figure 4(a1) shows the $\mathrm{ZnO}$ fibers synthesized at $160^{\circ} \mathrm{C}$; Figure $4(\mathrm{a} 2)$ is a partial enlargement of Figure 4(a1). Figure 4(a3) is the selected area electron diffraction (SAED) graph of the $\mathrm{ZnO}$ fibers; some crystals, speculated as $\mathrm{ZnO}$ fiber structures, are already apparent. Figure $4(\mathrm{~b} 1)$ is an image of the $\mathrm{ZnO}$ fibers calcinated at $500^{\circ} \mathrm{C}$; Figure 4 (b2) is a partial enlargement of Figure 4(b1). Figure 4(b3) exhibits the SAED graph following calcinations, revealing superior crystallinity to that in Figure 4(a3). Figures 5(a1) and 5(a2) are the SAED graphs of the $\mathrm{ZnO}$ flakes synthesized at $160^{\circ} \mathrm{C}$, and Figures 5(b1) and 5(b2) are the SAED graphs of the calcinated $\mathrm{ZnO}$ flakes. Figures 4 and 5 demonstrate that the number of holes and cracks increases when zinc alkoxide turns into $\mathrm{ZnO}$ during calcination. Moreover, the crystallinity improves, and 


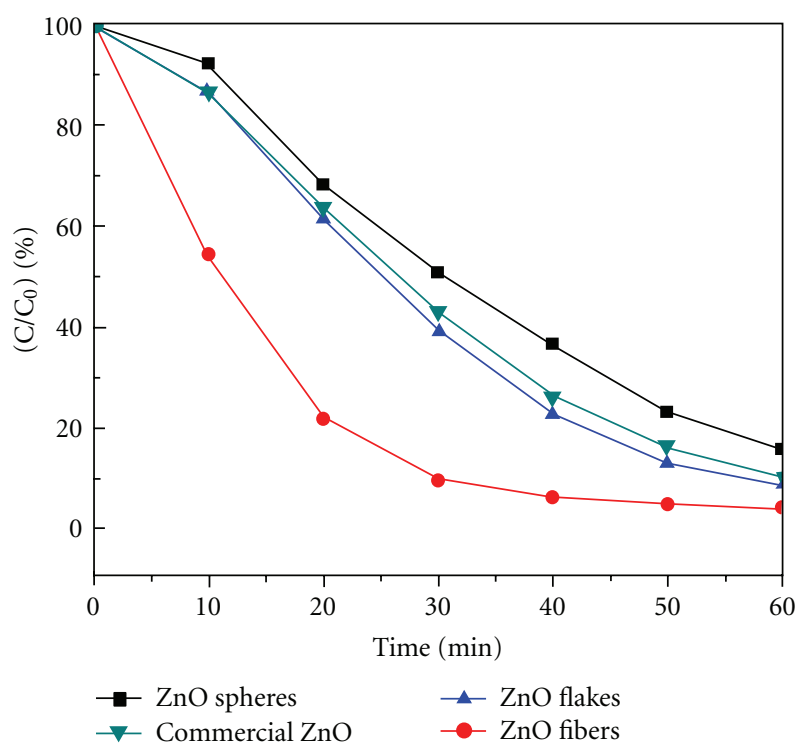

FIGURE 8: Comparison of photocatalytic effects of various $\mathrm{ZnO}$ structures.

polycrystalline structures form, which correspond with the XDR graphs.

The precursor solutions of the three different morphologies of $\mathrm{ZnO}$ were further analyzed by TGA/DSC to investigate the influence of the heat treatment on the samples. Figure 6 presents the results of the TGA/DSC analysis. Each sample exhibited a distinct endothermic peak followed by a marked loss in weight at the lower temperatures of $152.11^{\circ} \mathrm{C}, 230.18^{\circ} \mathrm{C}$, and $194.66^{\circ} \mathrm{C}$, respectively. The endothermic peaks and weight loss are primarily caused by the vaporization of the alcohols in the solution, leaving zinc alkoxide behind. Furthermore, the three different surface morphologies of $\mathrm{ZnO}$ showed exothermic peaks at $306.31^{\circ} \mathrm{C}$, $365.51^{\circ} \mathrm{C}$, and $285.81^{\circ} \mathrm{C}$, respectively, indicating the pyrolysis of zinc alkoxide and the energy required for it to sinter into $\mathrm{ZnO}$. As seen in Figure 6, spherical structures require the least amount of energy to be converted into $\mathrm{ZnO}$, thereby explaining the reason why the spherical sample is capable of forming crystalline $\mathrm{ZnO}$ structures at a lower temperature.

3.3. Formation Mechanism. Due to the heating, the $\mathrm{ZnAc}$ within the solution undergoes hydrolysis forming acetate ions and zinc ions. With the abundance of electrons in the oxygen atoms, the hydroxyl groups $(-\mathrm{OH})$ of alcohol molecules bond with the zinc ions. The resulting alkoxides are such as shown in (1)-(3). Figure 7 presents the bonding processes for $\mathrm{ZnO}$ fiber structures, sheet structures, and spherical structures. When using EG as the solvent, the two sides of the zinc ions form ionic bonds with the oxygen ions, which link to more ions and form long fiber-like structures (Figure 7(a)).

With $G$ as the solvent, the glycerol possesses three hydroxyl groups that can react with the zinc ions. Because the electronic configuration of the zinc ions is $[\mathrm{Ar}] 3 \mathrm{~d}^{10}$, $4 \mathrm{~s}$ and $4 \mathrm{p}$ merge into an empty $\mathrm{sp}^{3}$ orbital, which further forms coordinate covalent bonds with the oxygen ions in the alkoxy groups created by the glycerol. Under the conditions enabling the formation of coordinate covalent bonds with minimal three-dimensional obstacles, simulation showed the resulting sheet structures exhibited in (Figure $7(\mathrm{~b})$ ).

The reaction principles under the circumstances with DEG as the solvent are similar to those with glycerol. Due to the longer molecular structures of DEG and in consideration of conditions enabling the formation of coordinate covalent bonds with minimal three-dimensional obstacles, $3 \mathrm{D}$ structures are more probable (Figure 7(c)). These 3D structures form sphere colloid particles, which further cluster into larger spherical structures. As observed in microscopic images shown in Figure 2, the spherical structures are in fact clusters of smaller spherical structures:

$$
\begin{aligned}
& \mathrm{Zn}\left(\mathrm{CH}_{3} \mathrm{COO}\right)_{2}+\mathrm{HO}-\mathrm{CH}_{2} \mathrm{CH}_{2}-\mathrm{OH} \\
& \longrightarrow \mathrm{Zn}^{2+} \cdot{ }^{-} \mathrm{O}-\mathrm{CH}_{2} \mathrm{CH}_{2}-\mathrm{O}^{-}+2 \mathrm{CH}_{3} \mathrm{COO}^{-}+2 \mathrm{H}^{+} \\
& \frac{3}{2} \mathrm{Zn}\left(\mathrm{CH}_{3} \mathrm{COO}\right)_{2}+\mathrm{HO}-\mathrm{CH}_{2} \mathrm{CHOHCH}_{2}-\mathrm{OH} \\
& \longrightarrow \frac{3}{2} \mathrm{Zn}^{2+} \cdot{ }^{-} \mathrm{O}-\mathrm{CH}_{2} \mathrm{CHOHCH}_{2}-\mathrm{O}^{-} \\
& +3 \mathrm{CH}_{3} \mathrm{COO}^{-}+3 \mathrm{H}^{+} \\
& \mathrm{Zn}\left(\mathrm{CH}_{3} \mathrm{COO}\right)_{2}+\mathrm{HO}_{-} \mathrm{CH}_{2} \mathrm{CH}_{2} \mathrm{OCH}_{2} \mathrm{CH}_{2}-\mathrm{OH} \\
& \longrightarrow \mathrm{Zn}^{2+} \cdot{ }^{-} \mathrm{O}-\mathrm{CH}_{2} \mathrm{CH}_{2} \mathrm{OCH}_{2} \mathrm{CH}_{2}-\mathrm{O}^{-} \\
& +2 \mathrm{CH}_{3} \mathrm{COO}^{-}+2 \mathrm{H}^{+} .
\end{aligned}
$$

3.4. Photocatalytic Activity Test. $4 \mathrm{~mL}$ of $5 \mathrm{ppm}$ methylene blue solution was respectively added to $0.1 \mathrm{~g}$ of the three types of $\mathrm{ZnO}$ and commercial $\mathrm{ZnO}$, followed by irradiation with $254 \mathrm{~nm}$ UV light. The degradation rate of $\mathrm{ZnO}$ fibers as the catalyst was the highest (Figure 8); after 10 minutes, the concentration of methylene blue reduced by $50 \%$. The concentrations of the methylene blue solutions added to the $\mathrm{ZnO}$ sheets, $\mathrm{ZnO}$ spheres, and commercial $\mathrm{ZnO}$ were still approximately $90 \%$. The degradation rates from the highest to the lowest were $\mathrm{ZnO}$ fibers $>\mathrm{ZnO}$ sheets $>$ commercial $\mathrm{ZnO}>\mathrm{ZnO}$ spheres.

\section{Conclusion}

This study employed the sol-gel method to synthesize $\mathrm{ZnO}$ polycrystalline nanostructures using ZnAc as the solute and various polyols as solvents (EG, G, and DEG). Zinc alkoxide crystals of varying morphologies were successfully fabricated at $160^{\circ} \mathrm{C}$. The EG, G, and DEG solvents synthesized fiberlike nanostructures, rhombic flakes, and spherical particles, respectively. The surface morphology of the samples dried at $160^{\circ} \mathrm{C}$ was smooth. By contrast, the samples calcinated at $500^{\circ} \mathrm{C}$ in air gained sufficient energy to enable pyrolysis of the zinc alkoxide and sintering into the smaller $\mathrm{ZnO}$ molecules. Consequently, a considerable number of cracks and holes appeared, which, however, had no effect on the overall morphology. The XRD graphs and FE-TEM images mutually verify the increase in crystallinity following calcination as well as the polycrystalline structures of $\mathrm{ZnO}$. 
By the results, we proposed models of the relevant formation mechanisms taking into account ionic bonding and threedimensional obstacles. A photocatalyst activity test was performed on the synthetic products and the commercial $\mathrm{ZnO}$. The results indicate that the catalytic effect of $\mathrm{ZnO}$ fibers was the most effective.

\section{References}

[1] D. C. Look, J. W. Hemsky, and J. R. Sizelove, "Residual native shallow donor in ZnO," Physical Review Letters, vol. 82, no. 12, pp. 2552-2555, 1999.

[2] Y. W. Heo, D. P. Norton, L. C. Tien et al., "ZnO nanowire growth and devices," Materials Science and Engineering R, vol. 47, no. 1-2, pp. 1-47, 2004.

[3] K. Ellmer, "Resistivity of polycrystalline zinc oxide films: current status and physical limit," Journal of Physics D, vol. 34, no. 21, pp. 3097-3108, 2001.

[4] A. Ohtomo, M. Kawasaki, Y. Sakurai et al., "Fabrication of alloys and superlattices based on $\mathrm{ZnO}$ towards ultraviolet laser," Materials Science and Engineering B, vol. 56, no. 2-3, pp. 263-266, 1998.

[5] J. Wang and L. Gao, "Synthesis and characterization of $\mathrm{ZnO}$ nanoparticles assembled in one-dimensional order," Inorganic Chemistry Communications, vol. 6, no. 7, pp. 877-881, 2003.

[6] A. Kajbafvala, M. R. Shayegh, M. Mazloumi et al., "Nanostructure sword-like $\mathrm{ZnO}$ wires: rapid synthesis and characterization through a microwave-assisted route," Journal of Alloys and Compounds, vol. 469, no. 1-2, pp. 293-297, 2009.

[7] P. Li, Y. Wei, H. Liu, and X. Wang, "A simple low-temperature growth of $\mathrm{ZnO}$ nanowhiskers directly from aqueous solution containing $\mathrm{Zn}(\mathrm{OH})_{4}{ }^{2-}$ ions," Chemical Communications, no. 24, pp. 2856-2857, 2004.

[8] S. W. Kuo, Y. C. Chung, K. U. Jeong, and F. C. Chang, "A simple route from monomeric nanofibers to zinc oxide/zinc sulfide nanoparticle/ polymer composites through the combined use of $\gamma$-irradiation polymerization, gas/solid reaction and thermal decomposition," Journal of Physical Chemistry C, vol. 112, no. 42, pp. 16470-16477, 2008.

[9] C. Bae, H. Yoo, S. Kim et al., "Template-directed synthesis of oxide nanotubes: fabrication, characterization, and applications," Chemistry of Materials, vol. 20, no. 3, pp. 756-767, 2008.

[10] Q. Cui, K. Yu, N. Zhang, and Z. Zhu, "Porous ZnO nanobelts evolved from layered basic zinc acetate nanobelts," Applied Surface Science, vol. 254, no. 11, pp. 3517-3521, 2008.

[11] L. Wu, Y. Wu, and Y. Lü, "Self-assembly of small $\mathrm{ZnO}$ nanoparticles toward flake-like single crystals," Materials Research Bulletin, vol. 41, no. 1, pp. 128-133, 2006.

[12] S. -H. Yu and M. Yoshimura, "Shape and phase control of $\mathrm{ZnS}$ nanocrystals: template fabrication of wurtzite $\mathrm{ZnS}$ single-crystal nanosheets and $\mathrm{ZnO}$ flake-like dendrites from a lamellar molecular precursor $\mathrm{ZnS} \cdot\left(\mathrm{NH}_{2} \mathrm{CH}_{2} \mathrm{CH}_{2} \mathrm{NH}_{2}\right)_{0.5}$," Advanced Materials, vol. 14, no. 4, pp. 296-300, 2002.

[13] S. Chen, Y. Liu, C. Shao et al., "Structural and optical properties of uniform $\mathrm{ZnO}$ nanosheets," Advanced Materials, vol. 17, no. 5, pp. 586-590, 2005.

[14] L. Tang, S. Yang, Y. Guo, and B. Zhou, "Building blocktunable synthesis of self-assembled $\mathrm{ZnO}$ quasi-microspheres via a facile liquid process," Chemical Engineering Journal, vol. 165 , no. 1, pp. 370-377, 2010.
[15] H. Wang, K. P. Yan, J. Xie, and M. Duan, "Fabrication of ZnO colloidal photonic crystal by spin-coating method," Materials Science in Semiconductor Processing, vol. 11, no. 2, pp. 44-47, 2008.

[16] W. Lee, M. C. Jeong, and J. M. Myoung, "Catalyst-free growth of $\mathrm{ZnO}$ nanowires by metal-organic chemical vapour deposition (MOCVD) and thermal evaporation," Acta Materialia, vol. 52, no. 13, pp. 3949-3957, 2004.

[17] B. P. Zhang, N. T. Binh, K. Wakatsuki et al., "Pressuredependent $\mathrm{ZnO}$ nanocrsytal growth in a chemical vapor deposition process," Journal of Physical Chemistry B, vol. 108, no. 30, pp. 10899-10902, 2004.

[18] Y. W. Wang, L. D. Zhang, G. Z. Wang, X. S. Peng, Z. Q. Chu, and C. H. Liang, "Catalytic growth of semiconducting zinc oxide nanowires and their photoluminescence properties," Journal of Crystal Growth, vol. 234, no. 1, pp. 171-175, 2002.

[19] M. H. Huang, Y. Wu, H. Feick, N. Tran, E. Weber, and P. Yang, "Catalytic growth of zinc oxide nanowires by vapor transport," Advanced Materials, vol. 13, no. 2, pp. 113-116, 2001.

[20] C. H. Liu, W. C. Yiu, F. C. K. Au, J. X. Ding, C. S. Lee, and S. T. Lee, "Electrical properties of zinc oxide nanowires and intramolecular p-n junctions," Applied Physics Letters, vol. 83, no. 15, pp. 3168-3170, 2003. 

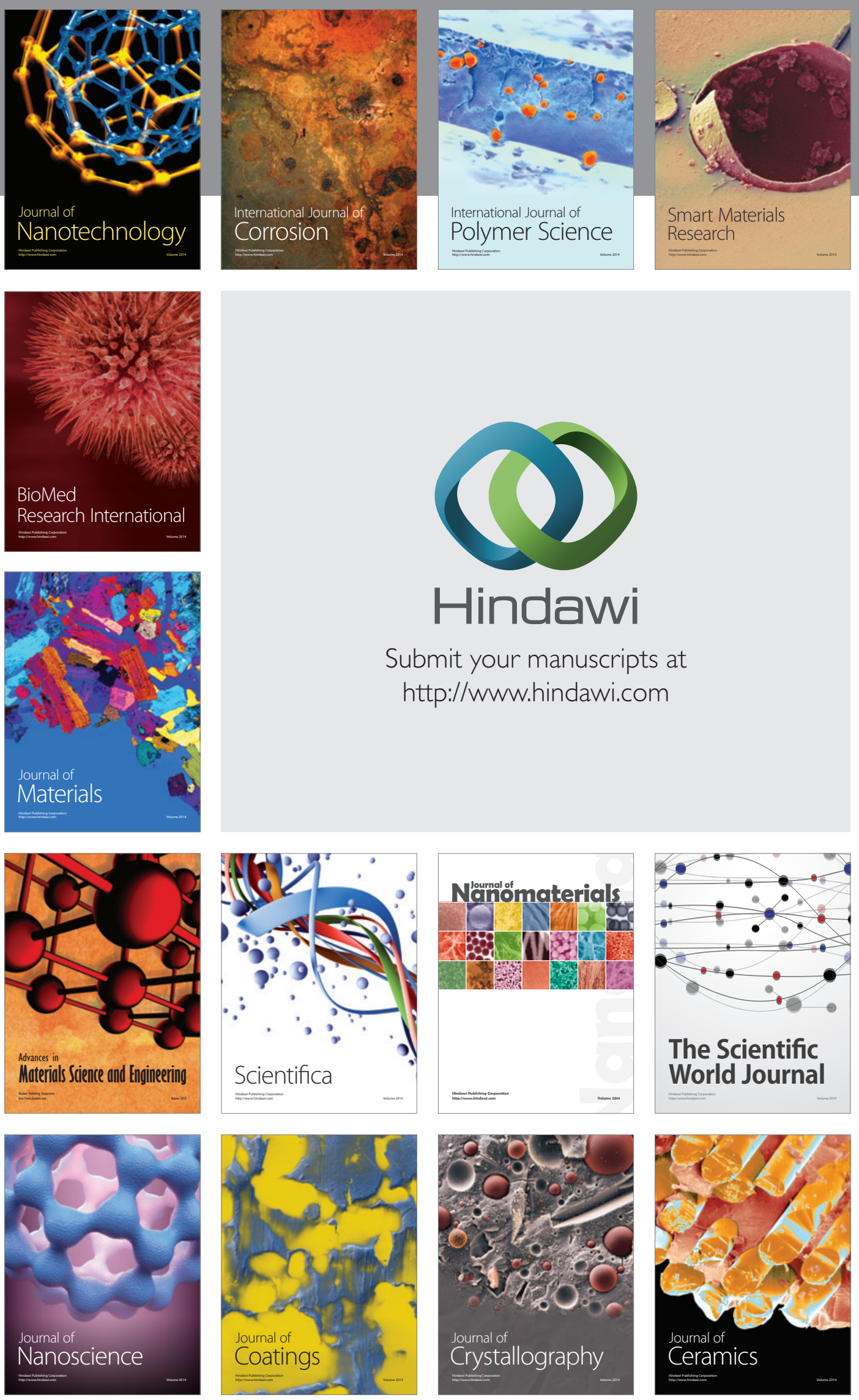

The Scientific World Journal

Submit your manuscripts at

http://www.hindawi.com

\section{World Journal}

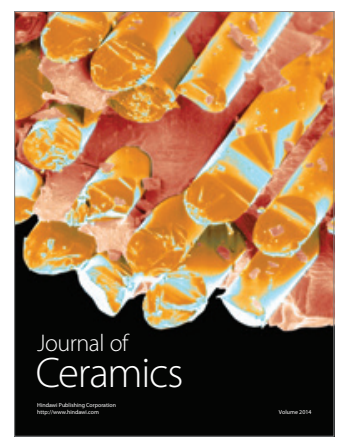

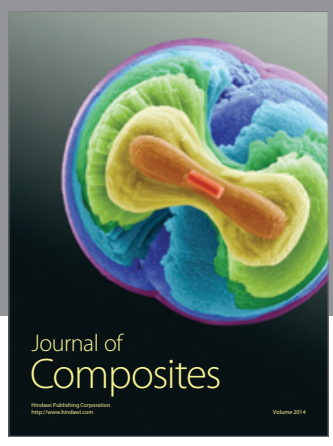
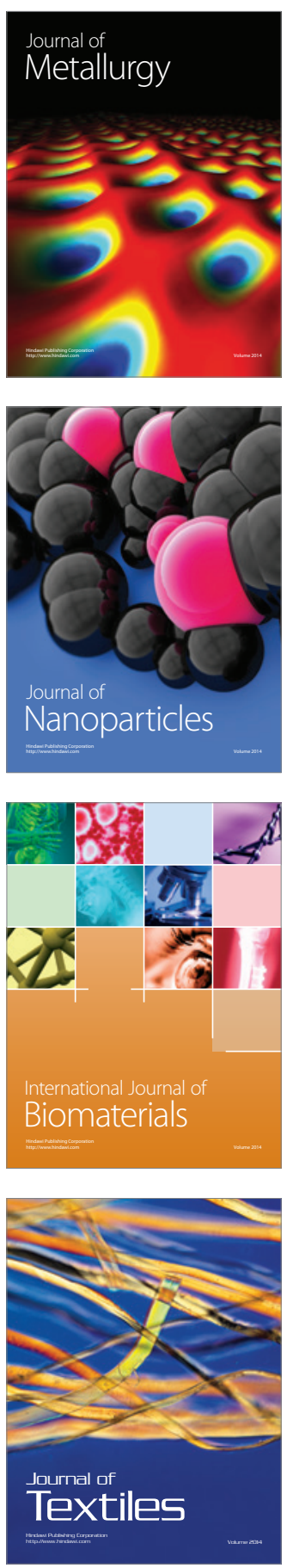